\title{
O DISCURSO DA LIBERDADE: O DITO E O VISTO
}

Eliane Patrícia G. Serrano - UNESP - Presidente Prudente

Guiomar J. Biondo - UNESP - Bauru

Nelyse Ap. Melro Salzedas - UNESP - Assis e Bauru

O "insight" desta proposta vem de Starobinski, no livro A invenção de liberdade (1994), e de Peter Burke em Testemunha ocular (2004).

$\mathrm{O}$ discurso da história, seja ele falado, escrito ou visto, liga-se ao processo comunicativo, através da imagem, do som, das letras. Como em Altamira, nos textos pictóricos deixados nas cavernas. São eles as fontes primárias da história do pensamento e da cultura. A liberdade do homem insere-se naqueles conceitos.

Quebrando a linha da temporalidade e da espacialidade, três pintores, dois espanhóis e um francês documentaram pelos pincéis o valor e o preço da liberdade.

Pela linha temporal Goya, Delacroix e Picasso narraram e mostraram a luta contra o poder autoritário e o seu custo; pela linha da espacialidade a Espanha separa-se da França, mas unem-se pelo pensamento libertário.

Goya, com o Fuzilamento em 3 de maio de 1808 (1814); Delacroix, com A Liberdade guiando o povo (1830); Picasso , com Massacre na Corea (1951), fecham um círculo sobre a opressão de dominadores franceses e americanos.

Tais textos não documentam e não fruem isoladamente a arte e a história, um outro texto verbal, atual, também trabalha a pertinência da liberdade: A Ilha de Carlos Drumond de Andrade " A ilha é, afinal das contas, o refúgio último da liberdade, que em toda parte se busca destruir. Amemos a ilha".

Nas telas e no texto verbal há a marca do valor maior do homem: a liberdade, que os autores caracterizaram como ícones do grito da angustia e da revolta, tornando tais textos testemunhas oculares da história.

Pelas imagens vê-se em Goya, soldados franceses sem rosto, uniformizados; em Delacroix uma mulher-símbolo que ergue os braços em direção a luta e em Picasso os soldados são homens-robôs, treinados para matar. Tais cenas revelam um compromisso político dos pintores, cuja produção se denomina hoje "objetos de reportagem".

As leituras dos textos pictóricos podem ser iniciadas pela edição da Gallimard, Goya de sangre y oro, e posteriormente da Aguilar (1989) 
iniciam o livro com O Fuzilamento (1808) ladeado por um texto de Paul Morand que transcreveu: "Em tres de maio, os franceses são donos de Madri. No Ministério dos Correios toma acento seu tribunal militar, desde o amanhecer até a noite, as carretas atravessam a rua, cheias de patriotas silenciosos, com a camisa aberta, as mãos presas e amarradas às costas. São fuzilados em grupo, em filas, aos montes, no Retiro, na Casa de Campo, na montanha do Príncipe Pio, no convento de Jesus, na igreja Bom Sucesso, na porta de Segóvia, etc. No final do dia, o tribunal francês já não os julga". É esse recorte que Goya documenta em sua tela "O Fuzilamento". O cenário, as filas, os franceses, os patriotas constróem a paisagem e a ação da Guerra, vinte e quatro gravuras também participam dessa temática.

Em O Fuzilamento, os amotinados são mortos. Um homem de camisa branca, ajoelhado, com braços levantados, oferece-se de peito aberto às balas, desafiando o pelotão da execução. Os soldados franceses são vistos de costas, de pé, inclinados, juntos, como se fossem uma peça mecânica para matar, sem rosto, sem alma. A seus pés uma lanterna de forma cúbica iluminava a cena e focalizava aqueles que deveriam ser atingidos. Paralela a diagonal que traçava a posição francesa, com a dos espanhóis amotinados. Um bloco de corpos ensanguentados, enfatizando um padre pelo hábito e tonsura, fecha a tela. Os personagens presentes afrontam os soldados de Bonaparte, não são figurantes, pertencem ao acontecimento histórico.

Ferrier aponta que, antes de Goya, a pintura da história era uma arte aparatosa, suas pinturas mexem com o gênero. Seus heróis são camponeses que combatem com o mesmo vigor de um soldado do exército imperial e "seu quadro é um hino à resistência do povo contra o opressor" (F - 1996). Certamente, Goya selecionou o momento de maior tensão dos acontecimentos: opor o peito aberto do amotinado à fila passiva daqueles que já aceitaram o fuzilamento. As cores amarelas e vermelhas acentuam o conflito; homens com rosto e sem rosto marcam o perfil libertário e autoritário. O cenário, a montanha, o vale, a igreja é maior que a força conquistadora dos franceses - a Espanha e seus homens não se subjugam.

A fila de homens componentes da tela, como disse Ferrier, também não é uma ilustração aparatosa de um acontecimento, é um documentário, por isso $\mathbf{O}$ Fuzilamento ocupa no Prado uma única parede. O leitor, ante ela e nada mais, ele pode ignorar o acontecimento histórico, mas o grupo de soldados sem rosto, a fila a espera do fuzilamento, o homem de camisa, de joelhos, de braços abertos, em uma atitude de coragem e certeza, ele não pode deixar de olhar e, sobretudo, de ver. E 
como "diz" a tela, numa relação entre o dito e o visto, o homem de camisa branca e braços levantados, é o único iluminado.

A segunda leitura pictórica concorda com Peter Burke que diz que as imagens não devem ser consideradas simples reflexões de sua época e lugar, mas são extensões dos contextos sociais em que foram produzidas e se usadas hoje devem ser interpretadas e aplicadas para que se faça novos julgamentos numa atualização para o contexto atual, deixando criar uma nova imaginação histórica.

Em “A liberdade guiando o povo"de Delacroix, revela a mulher personificada de liberdade que foi tema tratado desde a Grécia antiga, mas foi a partir da revolução Francesa que o lema Liberdade, Fraternidade e Igualdade foi representado visualmente, por essa razão que Delacroix, através de uma pintura representou a mulher simbolizando uma idéia.

A idéia de representar a mulher deve-se ao fato que um objeto tanto pode representar coisas do mundo visível quanto uma idéia, nesse caso um simples gesto de levantar a mão, proclama a vitória. A mulher liberdade, simboliza aquela que dá a luz, que faz nascer uma nova vida, uma nova cultura, tinha como propósito fazer nascer os ideais de renovação política de se criar novos conceitos propagados pela revolução francesa.

Essa obra nos oferece uma interpretação contemporânea do evento de 1830, associados aos ideais da revolução de 1789, que se assemelha a prática comunicacional da Revolução Russa, construída nos moldes marxistas, transmitida de forma visual, (pintura), porém, dentro de uma estética romântica, com influência renascentista e barroca dada a sua composição cujo colorido trágico nos leva à obscuridade do lago do inferno descrito por Dante na Divina Comédia, revelando o seu gosto pela leitura que muito lhe ajudou a progredir nas guerras da vida. O drama das narrativas combina com o temperamento de Delecroix, dando asas a sua imaginação: o terrível, o absurdo, o trágico e o cômico despertou sua admiração pela anatomia no dramático e na expressão do sofrimento humano. A composição centrada dentro de uma estrutura geométrica sólida ( pirâmide, espiral, esfera), leva o espectador a percorrer com o olhar todo o quadro e mediante o ritmos e a luminosidade, vem colocar esse espectador como testemunha dos acontecimentos.

É uma composição política que marcou um momento no qual o romantismo abandonou as suas raízes de inspiração clássica, para assumir destaque na vida contemporânea. Foi ai que Delacroix escreveu a seu irmão, o "general". Construí um tema moderno,já que não lutei, nem conquistei nada pela pátria, posso, ao menos, pintar por "ela" e assim 
alistou-se como garde national, e neste papel retratou-se a si próprio, a esquerda da liberdade, usando uma cartola.

Delacroix amava as mulheres, foi o artista mais adequado para representar a mulher moderna na sua manifestação heróica podendo ser ela infernal ou divina.. A beleza física dessas mulheres é uma idéia revolucionária: tem um ar de rêverie, seios grandes, vasta pélvis ,tronco estreito, braços e pernas encarnadas. Não pintou mulheres bonitas do ponto de vista da sociedade da época, mas elas resplandecem com sua beleza interior, representando a força não pelo tamanho dos músculos, mas pela tensão nervosa, transmitindo a luta pela angustia moral. instante?

Mas que mulher é essa que guiou o povo? Que fazia naquele

A cena é única, a catástrofe da guerra.

Em conseqüência do acontecimento, seu objetivo não era de descrever o acontecimento, mas fazer com que o espectador sentisse as suas conseqüências emocionais e a mulher foi a portador da bandeira da liberdade, aquela que abandonou o lar para abraçar uma grande causa da liberdade.

Uma mulher do povo, uma vendedora de peixe, uma Vênus da rua e não uma condessa de Faubourg Saint-Germin. Essa foi uma visão romântica de apreciar as tragédias, os sacrifícios do povo, representando uma mulher comandando a barricada. Um louvor à mulher.

O erotismo dos seios desnudos, a sujidade da saia os pelos das axilas, indicam que a deusa da liberdade era uma mulher do povo. Os seios descobertos também revela um ícone político derivado em parte da nudez iconográfica dos santos, e a sua liberdade pertence a tradição das madonas sadomasoquistas pintadas para as igrejas.

Os cadáveres debaixo de seus pés descalços enquanto guia a multidão enfurecida, foi um tributo a libertada, eles aparecem para dar forma as virtudes sociais, do republicanismo, posição essa oficialmente reconhecida pela difusão da imagem. Esse nacionalismo transmitido de forma visual pelos artistas foi uma solução concreta encontrada pelos meios oficiais (reis-cidadões) para divulgar suas idéias e valores. A obra além de representar a mulher, a criadora, foi uma forma de propaganda do novo símbolo da França, a sua bandeira colorida, expõe o nacionalismo em forma de arte, uma solução que até hoje perdura nos meios de comunicação de massa como ocorreu nos últimos acontecimentos franceses por ocasião das eleições presidências quando os jornais apresentaram uma foto em que 
um simpatizante da socialista Ségolène Royal, saiu as ruas com uma bandeira empunhando o gesto de liberdade com os punhos levantados.

A última leitura, é uma atualização da primeira tela analisada. Em 1951, Picasso expõe, mais uma vez, seu compromisso político através da pintura. Produz um texto plástico, cuja dramaticidade exala pelos poros cromáticos e formais da tela. "Massacre em Corea" representa o momento pré-fuzilamento de soldados americanos contra mulheres e crianças coreanas. Trata-se de um quadro extremamente marcante, não apenas pelo chocante tema, a morte de inocentes, mas principalmente por sua concepção plástica.

A composição se divide em três momentos: o passado, o presente e o futuro.

O grupo de soldados armados de um lado, representados com estranhas armas e de forma robótica, mirando para o grupo de mulheres e crianças aterrorizados pelo o que está por acontecer. Os militares apresentam-se não como humanos mas como máquinas mortíferas, sem rostos, com exceção de um que se apresenta de forma diferente, possui roupas que remetem o espectador a um tempo passado (idade média) e suas armas não são de fogo, tem uma espada e um pedaço de madeira, o seu rosto aparece em três quartos. A marca temporal reside justamente na forma e no conteúdo dos personagens. O passado pelo soldado diferente, que se dispõe a matar, mas por uma causa, por uma luta humana; o presente nos soldados robôs que se enquadram dentro do sistema da guerra, que mata sem causa aparente e o futuro representado pelas mulheres que esperam, que possuem um sopro de vida, muitas estão grávidas e as crianças que às vezes nem percebem o perigo e continuam no mundo imaginário; todo o movimento temporal em contraste com uma paisagem desolada, sem sombras, com imensos vazios e profundos abismos, atemporal.

Por esta cena percebe-se ainda uma metáfora instigante através da falta de rosto dos militares e a fortes expressões fisionômicas dos massacrados, ou seja as expressões faciais de cada mulher e de cada criança revelam sensações inquietações, paixões, desejos , uma sucessão de sentidos que a qualquer momento poderão desaparecer, assim, metaforicamente observa-se um misto de niilismo (militares) e súplicas pela vida (mulheres e crianças).

Nesta leitura, o sentido da liberdade pode ser visto de maneira um pouco diferente daquele visto em Goya e Delacroix. O Fuzilamento de três de maio e a Liberdade guiando o povo, mostra o contraste vida e morte. 
Assim como em o Massacre em Corea, porém nos dois primeiros os mortos atingiram esta condição pelo desejo de se proclamar a luta pela liberdade; no caso do grupo coreano, que apesar de não terem sido representados pela morte física, eles não tiveram chance de optar por outra situação, a liberdade lhes foi tirada de forma irreversível.

Todos os textos têm como tema a liberdade, buscada e desejada por muitos, os artistas viram ou vivenciaram a história e deixaram como testemunho suas imagens que dizem muito mais do que se pode averiguar em breves leituras.

Por fim, lembremos as palavras de A Ilha de Carlos Drumond de Andrade "A ilha é, afinal das contas, o refúgio último da liberdade, que em toda parte se busca destruir. Amemos a ilha".

\section{Bibliografia}

ARGAN, Giulio Carlo e FAGIOLO, Maurizio. Guia de História da Arte. Trad. Maria Fernanda Gonçalves de Azevedo, Lisboa, Estampa, 1992.

ARGAN, Giulio Carlo. Arte moderna. S. Paulo: Cia das letras,1993.

BASTIDE, Jeannine. Goya de sangre y oro. Aguilar: Madrid, 1989

BURKE, Peter. Testemunha Ocular - História e Imagem. Tradução de Vera Maria Xavier dos Sanos; EDUSC: Bauru, SP; 2004.

ECO, Umberto. Sobre os espelhos e outros ensaios.Tradução de Beatriz Borges; Editora Nova Fronteira: Rio de Janeiro, 1989.

FERRIER, Jean-Louis. Les Aventures du Regard. J.C. Lattes: Paris, 1996.

FYTE, Gordon: Law, John. On the invisible of the visual (Ed.) Picturing Power. London. Routledge, 1988 .

GOMBRICH. E.H. A História da Arte.LTC: Rio de Janeiro, 1995.

NERET, Gilles . Eugéne Delacroix. Universidade de Harvard. Edições Taschen,1999. 